\title{
Parenting Stress, Social Support, and Depression for Ethnic Minority Adolescent Mothers: Impact on Child Development
}

\author{
Cindy Y. Huang, \\ Yale University School of Medicine, Department of Psychiatry, Division of Prevention and \\ Community Research, New Haven, CT 06511
}

Jessica Costeines, Yale University School of Medicine, Department of Psychiatry, Division of Prevention and Community Research, New Haven, CT 06511

Carmen Ayala, and Bridgeport Public Schools, Bridgeport, CT

Joy S. Kaufman

Yale University School of Medicine, Department of Psychiatry, Division of Prevention and Community Research, New Haven, CT 06511

Cindy Y. Huang: cindy.huang@yale.edu

\begin{abstract}
Rates of teenage pregnancies are higher for African American and Latina adolescents compared to their White peers. African American and Latina adolescent mothers also experience more adversities than their White peers, such as higher rates of depression, school dropout, and economic disadvantage. Furthermore, children of adolescent mothers are at higher risk for adverse development. Parenting stress and social support can impact outcomes experienced by adolescent parents and their children. The present study examined the influence of adolescent mothers' parenting stress and perceived social support on maternal depression at baseline (six months after birth), and its impact on infant development one year later (18 months after birth). Participants were 180 adolescent mothers of African American or Latino/Hispanic descent. Results suggest that higher levels of parenting stress and less perceived social support were associated with higher levels of depression in the adolescent mothers at baseline. Higher levels of maternal depression were also associated with more developmental delays in infants one year post-baseline. Additionally, depression mediated the relationship between parenting stress and later child outcomes. These findings highlight the importance of examining parenting factors such as parenting stress, social support, and maternal depression in ethnic minority adolescent parents, and provide valuable information regarding unique risk and protective factors associated with positive maternal outcomes for ethnic minority adolescent parents and healthy development for their children.
\end{abstract}

\section{Keywords}

parenting stress; social support; maternal depression; teen pregnancy; ethnic minority adolescents 


\section{Introduction}

Despite a steady decline over the past few decades, the rate of teenage pregnancies in the United States (U.S.) continue to be higher than most other developed nations (Singh \& Darroch, 2000). Rates of teenage pregnancies are even higher for African American and Hispanic/Latino adolescents compared to their White peers within the U.S. (Berry, Shillington, Peak, \& Hohman, 2000; East, Khoo, \& Reyes, 2006; Jahromi, Umana-Taylor, Updegraff, \& Lara, 2012). These patterns are concerning, given that adolescents who are parenting for the first time may experience additional stress and negative emotions associated with parenting (Hans \& Thullen, 2009), in turn impacting the healthy development of their children. In fact, infants of adolescent mothers are at higher risk for developmental delays and social-emotional problems (Lanzi, Bert, \& Jacobs, 2009; Smith, 2004) and are more likely to die during the first year of life (Coley \& Chase-Lansdale, 1998).

Compared to non-parenting adolescents, adolescent mothers are at higher risk for school dropout (Leadbeater, 1999) and added financial stress (Knitzer \& Perry, 2009). They are also at higher risk for negative mental health outcomes such as depression (Barnet, Joffe, Duggan, Wilson, \& Repke, 1996), and experience parenting-related stress (Emery, Paquette, $\&$ Bigras, 2008). Yet, the research focusing on mechanisms through which maternal mental health factors influence child development and outcomes for these adolescents and their children continue to be limited, especially for ethnic minority populations.

A breadth of literature has shown the negative impact of poor maternal mental health on healthy infant development. In particular, parental stress (e.g., stress in the parenting role) and depression are two common indicators of maternal distress that have demonstrated significant impact on child development. Research on adult mothers has linked higher levels of parental stress with poor child outcomes, such as separation anxiety (Deater-Deckard, Scarr, McCartney, \& Eisenberg, 1994), attention problems (DuPaul, McGoey, Eckert, \& VanBrakle, 2001), and depression (Anastopoulos, Guevremont, Shelton, \& DuPaul, 1992). Parents with higher parental stress have also been found to have more negative parenting styles (Deater-Deckard et al., 1994). These parenting styles are associated with poor behavioral, social-emotional, and cognitive outcomes in children, and can negatively influence the coping competence and ability in children whose parents have high levels of parenting stress (Cappa, Begle, Conger, Dumas, \& Conger, 2011).

A substantial body of literature also highlights the detrimental effects maternal depression has on the well-being of young children. Children whose mothers are depressed have more difficulties reaching development milestones (Field et al., 1996), less healthy attachment (Goodman \& Brand, 2011), more negative affect (Huot, Brennan, Stowe, Plotsky, \& Walker, 2004), and increased problems with self-regulation (Tronick \& Gianino, 2006; Zuckerman, Bauchner, Parker, \& Cabral, 1990). These findings are troublesome, as children with these difficulties are more vulnerable to later poor outcomes, including increased struggles with school adjustment (Sanson, Oberklaid, Pedlow, \& Prior, 2006), anxiety (Goodman \& Brand, 2011), and depression later in life (Beardslee, Versage, \& Gladstone, 1998; Beardslee, Wright, Gladstone, \& Forbes, 2007; Southam-Gerow \& Kendall, 2002). Furthermore, maternal depression has been characterized as a chronic, adverse experience that contributes to a toxic stress response in young children, leading to developmental delays and serious health concerns later on in life, such as diabetes, heart disease, and substance use (Shonkoff et al., 2012).

Similar to parenting stress, mothers with depression have been shown to be less reliable and less responsive to their infants, two critical factors in developing a healthy attachment 
between infant and mother (Goodman \& Brand, 2011). Research further indicates that women with depression are more likely to engage in negative parenting behaviors, such as being neglectful, coercive, or unpredictable (Goodman \& Brand, 2011; Shaw, Connell, Dishion, Wilson, \& Gardner, 2009).

For adolescent mothers, the likelihood of experiencing high levels of parental stress and depression are more pronounced since they are more likely to have social and economic burden, especially compared to adult mothers (Goodman \& Brand, 2011; Leadbeater, 1999; Spencer, Kalill, Larson, Spieker, \& Gilchrist, 2002). In fact, rates of parental stress are high among adolescent mothers of young children, with approximately $30 \%$ of mothers reporting clinically high levels of stress at any given time over a two-year period (Larson, 2004). Spencer and colleagues (2002) found that adolescent mothers continued to experience increased levels of parenting stress two years after the birth of their child. Adolescent mothers were found to spend most of their young adult years parenting alone and impoverished (Maynard, 1996), suggesting many adolescent mothers lack the resources and social support that can alleviate stressors associated with raising a young child. Additionally, rates of depression in adolescent mothers are higher than rates found for adult mothers of young children and non-parenting adolescents (Barnet et al., 1996; Lanzi et al., 2009; Mollborn \& Morningstar, 2009; Wilhelm, 2006).

Positive outcomes for both mother and child are associated with high levels of social support (Logsdon, Birkimer, Ratterman, Cahill, \& Cahill, 2002). Adolescent mothers who reside in multigenerational households with multiple sources of support are more likely to graduate from school (Gordon, Lindsay Chase-Lansdale, \& Brooks-Gunn, 2004). Studies have also shown that adolescent mothers with higher levels of support had less psychopathology and more positive attitudes toward parenting (Colletta, 1983; Crnic, Greenberg, Robinson, \& Ragozin, 1984). Adolescent mothers who have higher levels of social support (e.g., family, friends) have better mental health outcomes than those with less support (Bunting \& McAuley, 2004), and maternal support has been linked with an overall reduction in stress (Barth, Schinke, \& Maxwell, 1983). In addition, positive relationships with the child's father and a parental figure (e.g., the child's grandparent) are associated with lower rates of depression in adolescent mothers (Edwards et al., 2012). This support has been shown to aid in coping skills for stress and provide models for appropriate interactions between mother and child (Letourneau, Stewart, \& Barnfather, 2004).

While the literature indicates social supports as a protective factor for adolescent mothers and their children, there is evidence to suggest that adolescent mothers may have inadequate social support compared to adult mothers (Colletta, 1983; Logsdon et al., 2002). For instance, adolescent mothers have fewer friends in their social networks (Crinc et al., 1984) and are less likely to have the support of a partner compared to adult mothers (Garcia Coll, Hoffman, Houten, \& Oh, 1987). Conflictual relationships with family members, particularly with their mothers, are also associated with increased distress in adolescent mothers (Edwards et al., 2012; Garcia-Coll et al., 1987). As a result, the need to decrease mental health distress and increase social support of adolescent mothers is critical.

Research suggests ethnic minority adolescent parents may experience even more adversities than their White parenting peers (Milan et al., 2004), including higher risk for depression (Barnet et al., 1996; Birkeland, Thompson, \& Phares, 2005; Goodman \& Brand, 2011), school dropout (Leadbeater, 1999), and economic disadvantage (Miller \& Moore, 1990). One study found that Latina adolescents who were pregnant or parenting had lower levels of self-esteem, lower grades, and fewer career aspirations (Dogan-Ates \& Carrion-Basham, 2007). These findings are particularly concerning given the increased rates of teenage pregnancy in adolescents of color. 
Culturally-relevant factors may be at play in explaining the higher rates of teenage pregnancy for ethnic minority adolescents. Studies suggest that higher rates of teenage pregnancy can be found in Hispanic/Latino households that emphasize family or have favorable attitudes toward pregnancy (Rocca, Doherty, Padian, Hubbard, \& Minnis, 2010; Rocca, Hubbard, Johnson-Hanks, Padian, \& Minnis, 2010). These favorable attitudes have been shown to be connected to the higher levels of pregnancy intentions in Latina adolescents compared to non-Latina White and African American adolescents (Rocca, Doherty, et al., 2010). In spite of this research, more information is needed to fully understand the risks and protective factors associated with negative outcomes for ethnic minority adolescent mothers and their children.

While the relationship among parental stress, social support, and maternal depression are well established in the adult literature, further examination is needed for ethnic minority adolescent mothers. In particular, the ways in which maternal depression may mediate the relationship between parental stress and social support and later child developmental outcomes are not well understood. Thus, the present study proposed to address these gaps by examining the relationship among parenting stress, social support, and maternal depression in a sample of African American and Hispanic/Latina adolescent mothers. The impact of these factors on infant development at one year-follow up was explored. It was hypothesized that higher levels of parenting stress and lower levels of perceived support are associated with increased symptoms of depression in the adolescent mothers at six months, and higher levels of depression are associated with more delays in development for infants at one year. Also, maternal depression was hypothesized to mediate the relationship between parental stress and later infant development, and maternal social support and later infant development.

\section{Method}

This study utilized secondary data from a larger study evaluating the effectiveness of a pregnancy prevention program designed to increase parenting skills and increase maternal strengths for first time adolescent mothers. The larger study included an intervention group of financially disadvantaged adolescent mothers recruited through their schools, and a matched comparison group based on age, race/ethnicity, school status, and geographic area recruited from the Women, Infant and Children (WIC) office at a public health clinic. All participants needed to be under the age of 18 years and enrolled at a public school during the time of recruitment to be eligible for participation. Adolescent mothers and their parent or legal guardians provided consent/assent to participate in data collection. Semi-structured interviews were conducted when the infants were six months (Wave 1), one year (Wave 2), and 18 months (Wave 3) of age. All interviews were completed in participants' homes or schools. Participants received a $\$ 40$ gift card for participation in each interview. The Human Investigation Committee at the Yale University School of Medicine provided oversight of this study with regard to human subject's protection.

\section{Participants}

Participants included 180 African American or Latino/Hispanic adolescent mothers in an urban area in the Northeast (see Table 1 for demographic information). All variables of interest in this study were also examined in order to determine potential group differences between the intervention and control groups. Adolescents who received the intervention did not report significantly different levels of parental stress, perceived social support, or depression from those who did not receive the intervention. In addition, infant developmental outcomes did not differ by group. Thus, all analyses in this study were examined combining the intervention and control groups. 


\section{Measures}

Demographics-Participants provided information on their age, race/ethnicity, education level, and sources of financial support.

Parenting stress-The Parenting Stress Index Short Form (Abidin, 1990) is a 36-item measure used to determine the level of stress associated with parenting. Participants reported their level of agreement on a Likert scale of one to five, with higher scores indicating more stress. Parenting stress was collected at all waves; only scores from Wave 1 were used in this study. The PSI-SF yields a total parenting stress score as well as 3 subscale scores (parental distress, parent-child dysfunctional interaction and difficult child). Test-retest reliability for the PSI-SF Total Score has been reported at .84 and the Total Score of the PSI-SF has correlated well with the full length version of the PSI, .82 (Abidin, 1990).

Perceived social support-Participants reported on their perceived levels of social support on the Multidimensional Scale of Perceived Social Support (Zimet, Dahlem, Zimet, \& Farley, 1988), a 12-item measure that assesses three sources of support: family, friends, and significant other. Global support is also assessed. Adolescents indicated their level of agreement on a scale of one to seven, with higher scores indicating more support. While this measure was collected at all waves, only scores from Wave 1 were included in the analyses. Test-retest reliability has been reported at .85, and coefficient alphas have ranged from .77 to .92 for the overall scale (Zimet et al., 1988).

Maternal depression-Maternal depression was assessed using the Reynolds's Adolescent Depression Survey (Reynolds, 2002). The RADS-2 is a 30 item brief self-report measure that assesses the severity of depressive symptoms in adolescents. Participants reported their level of agreement on a scale of 1-4, with higher scores indicating more depression. The RADS-2 provides a total score as well as scores on four subscales: Dysphoric Mood, Anhedonia/Negative Mood, Negative Self Evaluation, and Somatic Complaints; the total score was utilized in this study. Maternal depression was assessed at all waves, but only Waves 1 and 2 were utilized in the analyses - Wave 1 depression was included as a control variable and Wave 2 was included as the mediator in the model. The RADS Total Scale has strong internal consistency (.93) and the internal consistency reliability on the four subscales ranges from .80 to .87 (Reynolds, 2002). High test-retest reliability have been found for the Depression Total Scales (.85) and test-retest reliability coefficients for the subscales are moderately high, ranging from .77 to .84 (Reynolds, 2002).

Child development-Children of the adolescent mothers were assessed for meeting developmental norms at all waves of the study using the Brigance Screens (Glascoe, 2002). The Brigance screens for age-appropriate development in the areas of receptive and expressive language gross and fine motor, socio-emotional development as well as self-help skills. Wave 1 (6 months of age) was included in the analyses as a control variable and Wave 3 (age 18 months) was included as the outcome of the study. Internal consistency, test-retest, and inter-rater reliability range from .98 to .99 on the infant and toddler version of the Brigance Screens (Glascoe, 2002). Overall developmental level quotient was used in the analysis for this study.

\section{Data Analysis}

A mediation path model was examined to determine the relationship among parenting stress, social support, and maternal depression (see Figure 1). Direct and indirect effects were examined using Mplus Version 7 software. Mplus 7 uses the maximum likelihood estimation (ML) method to estimate the model and obtain the variance-covariances of the parameters (Muthén \& Muthén, 2010). The ML estimation method automatically treated 
missing data using the listwise deletion (Muthén \& Muthén, 2010). We used the following indices to assess model fit: comparative fit index, or CFI, (Hu \& Bentler, 1999), with values greater than .95 indicating good model fit; root mean square error of approximation (RMSEA; Hu \& Bentler, 1999), with values less than .08 indicating reasonable model fit; and standardized root mean square residual (SRMR; Hu \& Bentler, 1999), with values less than .06 indicating good fit. A model was determined to fit well if these criteria were met. A statistical significance level of .05 was employed in evaluating the statistical significance of the direct and indirect mediating effects. To determine whether maternal depression was a significant mediator, Sobel tests were conducted to assess the statistical significance of indirect relationships (Preacher \& Hayes, 2004).

\section{Results}

Descriptive statistics for all variables were examined, including mean, standard deviation, and frequency distributions, to examine the tenability of assumptions required for the proposed statistical analyses. Correlations between independent variables were evaluated with a bivariate correlation matrix and found to be moderate, providing evidence that multicolinearity was not a problem. Extreme skew and kurtosis values were examined. The majority of study variables were found to be within the recommended limits of \pm 3.0 to 3.0 for skew values, and -10.0 to +10.0 for kurtosis values (Kline, 2010).

The mediation path model indicated good fit, $\chi^{2}(3)=5.45, p>.05, C F I=.96, R M S E A=.06$. Controlling for maternal depression at baseline (Wave 1), results revealed that higher levels of baseline parenting stress was associated with higher levels of maternal depression 6 months post-baseline $(\beta=.34, p<.001)$. Adolescents with less perceived social support at baseline also had higher levels of depression six months later (Wave $2 ; \beta=-.30, p<.001$ ). Furthermore, higher levels of parent depression at Wave 2 was associated with more developmental delays in infants one year later, or when the infants were 18 months old ( $\beta=$ $-.21, p<.05)$, even after controlling for infant development at baseline.

Sobel tests for mediation indicated adolescent maternal depression to be a significant mediator in the relationship between parenting stress and infant development at one year follow-up $(z=-3.07, p<.001)$, suggesting that maternal depression in part explains the influence of parenting stress on infant development. Maternal depression did not mediate the relationship between adolescents' levels of perceived social support and infant development at one year follow-up $(p=$ n.s.).

\section{Discussion}

This study examined the impact of maternal depression and parenting stress in ethnic minority adolescent mothers and their relationship to child development outcomes. Key findings indicated that a high level of parenting stress and low perceived social support were associated with higher levels of maternal depression at six-month follow up. Additionally, this high level of maternal depression is associated with greater developmental delays in infants at eighteen months of age.

As hypothesized, higher levels of parenting stress at Wave 1were associated with higher levels of depression at Wave 2 for ethnic minority adolescent mothers even after controlling for depression at Wave 1. This finding suggests that the stress associated with parenting, independent of previous levels of depression, plays a significant role in determining the mental health status of these adolescents. Conversely, higher levels of social support were associated with lower levels of depression. This is consistent with literature and further 
highlights the importance of having a network of support that can assist adolescent mothers with managing the stress of childrearing(Letourneau et al., 2004).

Maternal depression was found to be a mediator in the relationship between levels of parental stress and later infant development. This finding was expected given the existing literature on maternal depression and child outcomes (Field et al., 1996; Goodman \& Brand, 2011; Huot et al., 2004; Zuckerman et al., 1990), and suggests that maternal depression plays a role in infant development despite the influence of parenting stress. This finding also has significant implications for interventions, as supports focused on decreasing maternal depression pre- and postpartum can potentially mitigate negative influences of high parental stress and low social support for adolescent mothers. Since chronic levels of maternal depression and stress have considerable negative impact on infant development and outcomes (Shonkoff et al., 2012), these interventions can lead to promising efforts in the prevention of these negative outcomes for children.

Of additional significance is the replication of this finding demonstrating the relationship between maternal depression and child outcomes with a sample of ethnic minority adolescent mothers, especially since ethnic minority adolescent mothers have an increased likelihood of experiencing depression (Barnet et al., 1996; Birkeland et al., 2005; Milan et al., 2004). These results also underscore the need for further research on the role of depression, and its associated risks, for this vulnerable population in order to determine ways depression and stress can be minimized for these adolescents and their children.

Contrary to our hypothesis, maternal depression did not mediate the relationship between social support and infant development. This suggests that social support may more directly influence infant development for ethnic minority adolescent mothers. In addition, adolescents may have support systems (i.e., extended family, friends) beyond their parents who provide assistance with child care and parenting, which may in turn affect child development. Ethnic minority adolescent mothers are more likely to reside in homes with multiple supports beyond their parents due to family and cultural norms (Rocca, Doherty, et al., 2010). In fact, research has shown that ethnic minority adolescent mothers who live with multiple generations within a household (as opposed to just living with their parents) reported better outcomes for themselves and their children (Gordon et al., 2004), demonstrating that strong social support may play an even more significant role in the lives of ethnic minority adolescent mothers. Though these supports may play a large role in parenting for ethnic minority adolescent mothers, these relationships may not be reflected in our measure of social support; future studies should focus more specifically on these relationships for ethnic minority and White adolescent mothers in order to determine their levels of influence on adolescent maternal depression and child development.

\section{Limitations}

These findings contribute to the existing body of literature by illuminating how high parenting stress and low social support later impacts maternal depression, and in turn, child development, for ethnic minority adolescent mothers. However, limitations exist that warrant mentioning. First, social support was reported by the adolescent mothers based on their perception of the support they received, which may potentially differ from the actual level of support provided by family and other support systems. For instance, an adolescent who does not feel emotionally supported by her parents may rate parental support as low regardless of their financial or child rearing support. Future studies may benefit from including other measures of social support in order to more clearly capture the different types of support received by adolescent mothers. Furthermore, the majority of these interviews took place in the participants' homes where others were occasionally present, such as a guardian, friend, or neighbor. Though procedures were used that allowed the 
adolescent mothers to respond in a confidential manner, the presence of others in the home may have impacted the responses to questions pertaining to social support and symptoms of depression. Finally, this study examined the relationships among the variables of interest for African American and Hispanic/Latino adolescents together. In order to gather culturallyspecific information about the experiences of parenting adolescents of color, it is critical that future studies continue to examine both inter- and intra-group differences, as well as including cultural factors (e.g,. acculturation, ethnic or racial identity).

\section{Conclusions}

High levels of parenting stress and a lack of social support are associated with negative mental health status for ethnic minority adolescent mothers, which in turn negatively impacts the development of their children. In order to maintain healthy infant development, it is critical to explore ways to decrease stress and increase social supports available to ethnic minority adolescent parents (in order to decrease maternal depression). It is imperative that future studies explore unique risks and protective factors associated with positive maternal outcomes for ethnic minority adolescent parents to ensure healthy development for their children.

\section{Acknowledgments}

This publication was made possible by Grant Number APH PA 006041 from the U.S. Department of Health and Human Services. Support for Dr. Huang was provided by a National Institute on Drug Abuse (NIDA) funded Postdoctoral Training Program (T32 DA019426). The statements and opinions expressed are solely the responsibility of the authors and do not necessarily represent the official views of the Department or the National Institutes of Health.

\section{References}

Abidin, R. Parenting Stress Index (PSI) Manual. Odessa, FL: Psychological Assessment Resources: Inc; 1990.

Anastopoulos AD, Guevremont DC, Shelton TL, DuPaul GJ. Parenting stress among families of children with attention deficit hyperactivity disorder. Journal of Abnormal Child Psychology. 1992; 20(5):503-520. [PubMed: 1487593]

Barnet B, Joffe A, Duggan AK, Wilson MD, Repke JT. Depressive symptoms, stress, and social support in pregnant and postpartum adolescents. Archives of Pediatrics \& Adolescent Medicine. 1996; 150(1):64. [PubMed: 8542009]

Barth RP, Schinke SP, Maxwell JS. Psychological correlates of teenage motherhood. Journal of Youth and Adolescence. 1983; 12(6):471-487. [PubMed: 12339718]

Beardslee WR, Versage EM, Gladstone TR. Children of affectively ill parents: A review of the past 10 years. Journal of the American Academy of Child \& Adolescent Psychiatry. 1998; 37(11):11341141. [PubMed: 9808924]

Beardslee WR, Wright EJ, Gladstone TR, Forbes P. Long-term effects from a randomized trial of two public health preventive interventions for parental depression. Journal of Family Psychology. 2007; 21(4):703. [PubMed: 18179342]

Berry E, Shillington AM, Peak T, Hohman MM. Multi-ethnic comparison of risk and protective factors for adolescent pregnancy. Child \& Adolescent Social Work Journal. 2000; 17(2):79-96. doi: http://dx.doi.org/10.1023/A:1007554122283.

Birkeland R, Thompson JK, Phares V. Adolescent motherhood and postpartum depression. Journal of Clinical Child and Adolescent Psychology. 2005; 34(2):292-300. [PubMed: 15901229]

Bunting L, McAuley C. Research review: Teenage pregnancy and parenthood: The role of fathers. Child \& Family Social Work. 2004; 9(3):295-303.

Cappa KA, Begle AM, Conger JC, Dumas JE, Conger AJ. Bidirectional relationships between parenting stress and child coping competence: Findings from the PACE study. Journal of Child and Family Studies. 2011; 20(3):334-342. doi: http://dx.doi.org/10.1007/s10826-010-9397-0. 
Colletta ND. At risk for depression: A study of young mothers. Journal of Genetic Psychology. 1983; 142(2):301-310. [PubMed: 6875527]

Crnic KA, Greenberg MT, Robinson NM, Ragozin AS. Maternal stress and social support: Effects on the mother-infant relationship from birth to eighteen months. American Journal of Orthopsychiatry. 1984; 54(2):224-235. [PubMed: 6731590]

Deater-Deckard K, Scarr S, McCartney K, Eisenberg M. Paternal separation anxiety: Relationships with parenting stress, child-rearing attitudes, and maternal anxieties. Psychological Science. 1994; 5(6):341-346.

Dogan-Ates A, Carrion-Basham CY. Teenage pregnancy among Latinas: Examining risk and protective factors. Hispanic Journal of Behavioral Sciences. 2007; 29(4):554-569. doi: http:// dx.doi.org/10.1177/0739986307308163.

DuPaul GJ, McGoey KE, Eckert TL, VanBrakle J. Preschool children with attention-deficit/ hyperactivity disorder: impairments in behavioral, social, and school functioning. Journal of the American Academy of Child \& Adolescent Psychiatry. 2001

East PL, Khoo ST, Reyes BT. Risk and Protective Factors Predictive of Adolescent Pregnancy: A Longitudinal, Prospective Study. Applied Developmental Science. 2006; 10(4):188-199. doi: http://dx.doi.org/10.1207/s1532480xads1004_3.

Edwards RC, Thullen MJ, Isarowong N, Shiu CS, Henson L, Hans SL. Supportive relationships and the trajectory of depressive symptoms among young, African American mothers. Journal of Family Psychology. 2012; 26(4):585-594. doi: http://dx.doi.org/10.1037/a0029053. [PubMed: 22888784]

Emery J, Paquette D, Bigras M. Factors predicting attachment patterns in infants of adolescent mothers. Journal of Family Studies. 2008; 14(1):65-90. doi: http://dx.doi.org/10.5172/jfs. 327.14.1.65.

Field T, Estroff DB, Yando R, del Valle C, Malphurs J, Hart S. "Depressed" mothers' perceptions of infant vulnerability are related to later development. Child Psychiatry \& Human Development. 1996; 27(1):43-53. [PubMed: 8810115]

Garcia Coll CT, Hoffman J, Houten LJ, Oh W. The social context of teenage childbearing: Effects on the infant's care-giving environment. Journal of Youth and Adolescence. 1987; 16(4):345-360. [PubMed: 12280674]

Glascoe FP. The Brigance infant and toddler screen: standardization and validation. Journal of Developmental \& Behavioral Pediatrics. 2002; 23(3):145-150. [PubMed: 12055496]

Goodman SH, Brand SR. Infants of depressed mothers. Handbook of infant mental health. 2011; 153

Gordon RA, Lindsay Chase-Lansdale P, Brooks-Gunn J. Extended households and the life course of young mothers: Understanding the associations using a sample of mothers with premature, low birth weight babies. Child Development. 2004; 75(4):1013-1038. [PubMed: 15260862]

Hans SL, Thullen MJ. The relational context of adolescent motherhood. Handbook of infant mental health. 2009:214-229.

$\mathrm{Hu}, \mathrm{Lt}$; Bentler, PM. Cutoff criteria for fit indexes in covariance structure analysis: Conventional criteria versus new alternatives. Structural Equation Modeling: A Multidisciplinary Journal. 1999; 6(1):1-55.

Huot R, Brennan P, Stowe Z, Plotsky P, Walker E. Negative affect in offspring of depressed mothers is predicted by infant cortisol levels at 6 months and maternal depression during pregnancy, but not postpartum. Annals of the New York Academy of Sciences. 2004; 1032(1):234-236. [PubMed: 15677418]

Jahromi LB, Umana-Taylor AJ, Updegraff KA, Lara EE. Birth characteristics and developmental outcomes of infants of Mexican-origin adolescent mothers: Risk and promotive factors. International Journal of Behavioral Development. 2012; 36(2):146-156. doi: http://dx.doi.org/ 10.1177/0165025411430777. [PubMed: 22723720]

Kline, RB. Principles and practice of structural equation modeling. Guilford press; 2010.

Knitzer J, Perry D. Poverty and infant and toddler development: Facing the complex challenges. Handbook of infant mental health. 2009; 3:135-152. 
Lanzi RG, Bert SC, Jacobs BK. Depression Among a Sample of First-Time Adolescent and Adult Mothers. Journal of Child and Adolescent Psychiatric Nursing. 2009; 22(4):194-202. [PubMed: 19930300]

Larson NC. Parenting Stress among Adolescent Mothers in the Transition to Adulthood. Child \& Adolescent Social Work Journal. 2004; 21(5):457-476. doi: http://dx.doi.org/10.1023/B:CASW. 0000043359.38426.b4.

Leadbeater BJ. School outcomes for minority-group adolescent mothers at 28 to 36 months postpartum: A longitudinal follow-up. Cognitive and Moral Development, Academic Achievement in Adolescence. 1999; 2(4):237.

Letourneau NL, Stewart MJ, Barnfather AK. Adolescent mothers: Support needs, resources, and support-education interventions. Journal of Adolescent Health. 2004; 35(6):509-525. [PubMed: 15581532]

Logsdon CM, Birkimer JC, Ratterman A, Cahill K, Cahill N. Social support in pregnant and parenting adolescents: Research, critique, and recommendations. Journal of Child and Adolescent Psychiatric Nursing. 2002; 15(2):75-83. [PubMed: 12083755]

Maynard RA. Kids having kids: Economic costs and social consequences of teen pregnancy. 1996

Milan S, Ickovics JR, Kershaw T, Lewis J, Meade C, Ethier K. Prevalence, Course, and Predictors of Emotional Distress in Pregnant and Parenting Adolescents. Journal of Consulting and Clinical Psychology. 2004; 72(2):328-340. doi: http://dx.doi.org/10.1037/0022-006X.72.2.328. [PubMed: 15065965]

Miller BC, Moore KA. Adolescent sexual behavior, pregnancy, and parenting: Research through the 1980s. Journal of Marriage and the Family. 1990:1025-1044.

Mollborn S, Morningstar E. Investigating the relationship between teenage childbearing and psychological distress using longitudinal evidence. Journal of Health and Social Behavior. 2009; 50(3):310-326. [PubMed: 19711808]

Muthén, L.; Muthén, B. Mplus user's guide. 6th. Los Angeles, CA: Muthén \& Muthén; 2010. p. 1998-2010.

Preacher KJ, Hayes AF. SPSS and SAS procedures for estimating indirect effects in simple mediation models. Behavior Research Methods, Instruments, \& Computers. 2004; 36(4):717-731.10.3758/ BF03206553

Reynolds, WM. Reynolds Adolescent Depression Scale: RADS-2: Professional Manual. Psychological Assessment Resources; 2002.

Rocca CH, Doherty I, Padian NS, Hubbard AE, Minnis AM. Pregnancy intentions and teenage pregnancy among Latinas: A mediation analysis. Perspectives on Sexual and Reproductive Health. 2010; 42(3):186-196. doi: http://dx.doi.org/10.1363/4218610. [PubMed: 20887287]

Rocca CH, Hubbard AE, Johnson-Hanks J, Padian NS, Minnis AM. Predictive ability and stability of adolescents pregnancy intentions in a predominantly Latino community. Studies in Family Planning. 2010; 41(3):179-192. doi: http://dx.doi.org/10.1111/j.1728-4465.2010.00242.x. [PubMed: 21469271]

Sanson A, Oberklaid F, Pedlow R, Prior M. Risk indicators: Assessment of infancy predictors of preschool behavioural maladjustment. Journal of Child Psychology and Psychiatry. 2006; 32(4):609626. [PubMed: 1864892]

Shaw DS, Connell A, Dishion TJ, Wilson MN, Gardner F. Improvements in maternal depression as a mediator of intervention effects on early childhood problem behavior. Development and Psychopathology. 2009; 21(2):417. [PubMed: 19338691]

Shonkoff JP, Garner AS, Siegel BS, Dobbins MI, Earls MF, McGuinn L, Wood DL. The lifelong effects of early childhood adversity and toxic stress. Pediatrics. 2012; 129(1):e232-e246.10.1542/ peds.2011-2663 [PubMed: 22201156]

Singh S, Darroch JE. Adolescent pregnancy and childbearing: levels and trends in developed countries. Family Planning Perspectives. 2000:14-23. [PubMed: 10710702]

Smith M. Parental mental health: disruptions to parenting and outcomes for children. Child \& Family Social Work. 2004; 9(1):3-11. 
Southam-Gerow MA, Kendall PC. Emotion regulation and understanding: Implications for child psychopathology and therapy. Clinical Psychology Review. 2002; 22(2):189-222. [PubMed: 11806019]

Spencer MS, Kalill A, Larson NC, Spieker SJ, Gilchrist LD. Multigenerational coresidence and childrearing conflict: Links to parenting stress in teenage mothers across the first two years postpartum. Applied Developmental Science. 2002; 6(3):157-170. doi: http://dx.doi.org/10.1207/ S1532480XADS0603_5.

Tronick EZ, Gianino AF. The transmission of maternal disturbance to the infant. New Directions for Child and Adolescent Development. 2006; 1986(34):5-11.

Wilhelm K. Depression: From nosology to global burden. Women and depression: A handbook for the social, behavior, and biomedical sciences. 2006:3-21.

Zimet GD, Dahlem NW, Zimet SG, Farley GK. The multidimensional scale of perceived social support. Journal of Personality Assessment. 1988; 52(1):30-41.

Zuckerman B, Bauchner H, Parker S, Cabral H. Maternal depressive symptoms during pregnancy, and newborn irritability. Journal of Developmental and Behavioral Pediatrics. 1990

J Child Fam Stud. Author manuscript; available in PMC 2015 February 01. 


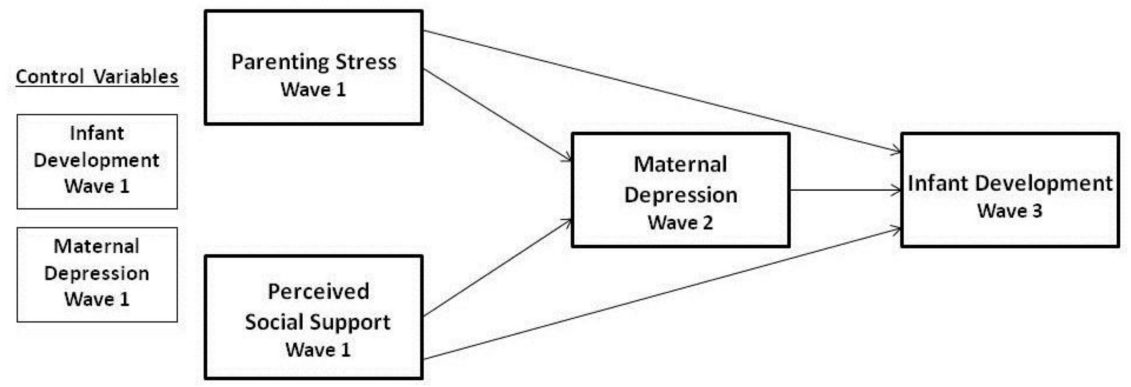

Figure 1.

Conceptual path model indicating adolescent mothers' parenting stress and perceived social support relating to maternal depression at six months and infant development at one year, controlling for infant development and maternal depression at baseline. 
Table 1

Demographic Information of Ethnic Minority Adolescent Mothers $(\mathbf{N}=\mathbf{1 8 0})$

\begin{tabular}{lcc}
\hline Child Characteristics & $\boldsymbol{n}$ & $\boldsymbol{\%}$ \\
\hline Age $(M=16.53, S D=2.30)$ & & \\
Race/Ethnicity & & \\
African/Black American & 73 & 40.56 \\
Hispanic/Latino & 107 & 59.44 \\
School Status & & \\
In School or GED Program & 123 & 68.33 \\
High School Graduate & 39 & 21.67 \\
High School Dropout & 11 & 6.11 \\
College or Trade School & 7 & 3.89 \\
Medicaid Support & & \\
Yes & 167 & 92.78 \\
No & 13 & 7.22
\end{tabular}

